\title{
“A IMPLACÁVEL SURDEZ DAS AUTORIDADES DO IMPÉRIO": as súplicas dos veteranos da Guerra do Paraguai (1870-1889)
}

\author{
Maria Regina Santos de Souza*
}

RESUMO: Depois da Guerra do Paraguai, o governo brasileiro não se importou com os direitos concedidos aos ex-combatentes, tais como pensões, empregos públicos, terras e compensação financeira. Isso se tornou um problema sério para os veteranos. Parte significativa deles também enfrentou a desorganização e a falta de conhecimento jurídico da burocracia do Estado. Este artigo aborda a luta dos veteranos do Ceará pelos direitos de guerra.

PALAVRAS-CHAVE: Guerra do Paraguai; Burocracia; Militar.

\section{"The implacable deafness of Imperial authorities": Veterans demands after the Paraguayan War (1870-1889)}

ABSTRACT: After the war in Paraguay, Brazilian government did not care for the rights granted to veterans, such as pensions, public jobs, land and finantial compensation. This became a serious problem for those veterans. Many faced the disorganization and lack of legal knowledge of the state bureaucracy.This article discusses the struggles of Veterans of Ceará for war rights.

KEYWORDS: Paraguayan War; Bureaucracy; Military.

\section{"La implacable sordera de las autoridades del Império": las súplicas de los veteranos de la Guerra del Paraguay (1870-1889)}

RESUMEN: Después de la Guerra del Paraguay, el gobierno brasileño no se preocupó con los derechos concedidos a los excombatientes, tales como pensiones, empleos públicos, tierras y compensación financiera. Eso representó un problema serio para los veteranos. Parte significativa de ellos también enfrentó la desorganización y la falta de conocimiento jurídico de la burocracia del Estado. Este artículo analiza la lucha de los veteranos del Ceará por los derechos de guerra.

PALABRAS CLAVE: Guerra del Paraguay; Burocracia; Militar.

\footnotetext{
*Doutora em História pela Universidade Federal de Pernambuco (UFPE). Pós-doutoranda em História (UFPE). Email: mamuk2013@yahoo.com.br
} 


\section{Introdução}

Após a Guerra do Paraguai (1864-1870), vários setores da sociedade brasileira - a exemplo das elites político-econômicas urbanas e de parte das autoridades militares - não esconderam o medo, a repulsa e a desconfiança que tinham em relação aos "veteranos do Paraguai", principalmente àqueles sem patente, os chamados praças (soldados, cabos, sargentos). No Ceará, por exemplo, esses militares eram, geralmente, vistos como “indivíduos ociosos com instintos homicidas" e, por isso mesmo, "pervertidos e pervertedores do povo", como disse o Jornal Cearense, na edição de 8 de agosto de 1875.

Essas imagens negativas sobre os "praças veteranos do Paraguai”, presentes nos jornais da capital cearense, Fortaleza, faziam parte de um conjunto de ideias pejorativas que circulavam pela imprensa nacional no pós-guerra. As vozes pareciam uníssonas em relação à “detração" desses militares. Basta uma ligeira análise em periódicos de grande circulação em outras capitais do Império, como Rio de Janeiro, cujo jornal A Reforma, por exemplo;afirmou, durante a década de 1870,que os regressos do Paraguai, sobretudo "os praças inválidos", não eram "heróis da pátria", mas "anti-heróis" desta; devido às desordens e aos crimes diversos que causavam na cidade.

Ao contrário do que grande parte da imprensa brasileira afirmava,os praças veteranos do Paraguai -sãos ou inválidos - não eram “criminosos ociosos e desordeiros”. Por meio da análise de fontes militares, como as dos Ministérios da Guerra e da Justiça - nas quais se encontram Requerimentos ou Súplicas despachados em nome de ex-combatentes do Paraguai, bem como em nome de familiares destes - percebe-se que muitos soldados, cabos e sargentos, oriundos principalmente das forças terrestres, procuraram ter uma vida considerada digna, longe da criminalidade.

De modo geral, esses militares pediam pensão e/ou meio soldo pelos serviços prestados nos campos de batalha paraguaios, mas havia também muitas solicitações de nomeações, empregos públicos, terras e gratificações em dinheiro, benefícios garantidos por leis e decretos militares brasileiros, por exemplo; o Decreto 3.371 dos Voluntários da Pátria, então baixado em 7 de janeiro de 1865, para as contingências do conflito.

A criação de corpos de Voluntários da Pátria foi uma especificidade da guerra do Paraguai e tinha como intuito "atender às graves e extraordinárias circunstâncias em que se achava o país, e a urgente e indeclinável necessidade de tomar, na ausência do corpo Legislativo, todas as providências para sustentação no exterior da Honra e Integridade do 
Império [...]", conforme afirmava o gabinete Liberal comandado pelo ministro Francisco José Furtado ${ }^{1}$.

No pós-guerra, todavia, a confusão, a desorganização e certa falta de conhecimentos presentes no corpo da burocracia do Estado,em relação aos decretos e às leis militares do Império, também impediram que muitos veteranos do Paraguai recebessem seus diretos de guerra. No caso dos praças regressos, esse conjunto de obstáculos era um problema a mais que eles tinham de enfrentar. Dessa forma, as súplicas desses militares quase sempre eram vistas com desconfiança pelas autoridades ministeriais, devido à imagem pejorativa que pairava sobre eles. No entanto, "baixos oficiais", como alferes e capitães, ainda que bem vistos, também foram prejudicados por aqueles problemas burocráticos ${ }^{2}$.

De resto, cabe perguntar: como isso foi possível? Um dos caminhos plausíveis é o acompanhamento das trajetórias percorridas pelos militares regressos do Paraguai, nos momentos de suas súplicas.

\section{As súplicas dos militares regressos}

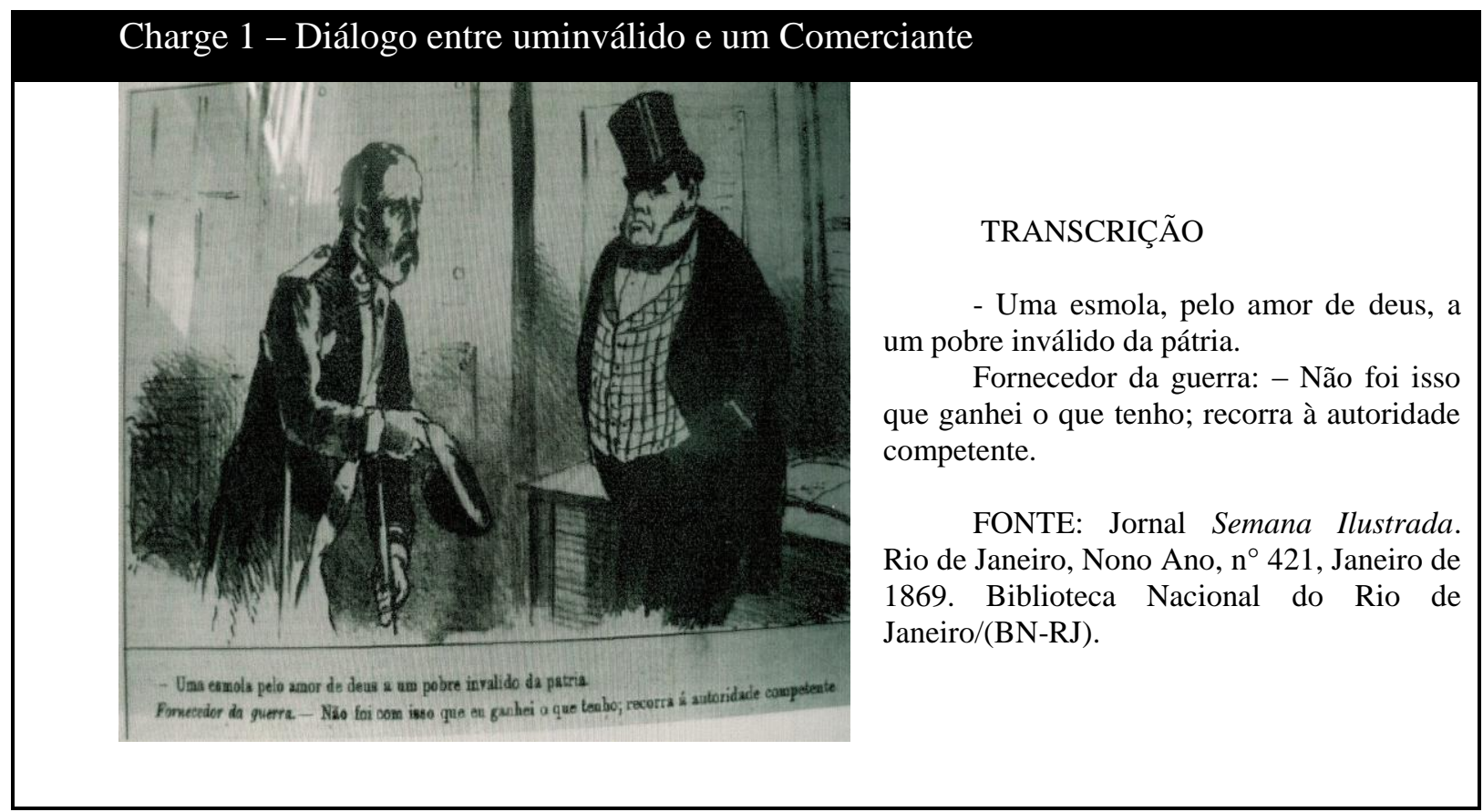

Um veterano da guerra do Paraguai esmolando. Esse tipo de imagem publicada pelo jornal carioca, Semana Ilustrada, no início de 1869, não era uma crítica isolada ao conflito. Fazia parte de um repertório bem conhecido na imprensa nacional, desde o segundo ano de combate, quando muitos militares, sobretudo os inválidos, começaram a retornar às províncias 
de origem. De certa forma, a charge indicava o que estava acontecendo e o que iria continuar a acontecer com os "heróis de guerra", caso a assistência social prometida pelo governo não fosse cumprida.

Em capitais provinciais como Fortaleza, onde não havia periódicos ilustrados especializados em imagens da guerra do Paraguai, as oposições vieram de forma escrita e extrapolaram os limites de 1870, quando foi anunciado o fim oficial do conflito. Além disso, algumas transcrições dos jornais da Corte eram feitas pela imprensa cearense, no intuito de deixar claro para as pessoas que,"no Império, não só os orphãos como os próprios voluntários da pátria, os heroes da guerra de honra, vivem por aí esmolando, abandonados à fome e à miséria" ${ }^{3}$.

As palavras da imprensa de Fortaleza não eram apenas retóricas, pois existia um correspondente social. A análise de documentos militares - como os requerimentos enviados da Presidência do Ceará ao Ministério da Guerra- mostrou que vários soldados, cabos e sargentos veteranos do Paraguai, todos de origem pobre, não tiveram qualquer amparo do governo. Imagine-se a dificuldade de sobrevivências desses militares.

Constatou-se também que o pagamento de pensão foi o benefício mais negado aos praças veteranos do Ceará. Dos duzentos requerimentos de pensão e/ou meio soldo catalogados nos Ofícios da Presidência do Ceará ao Ministério da Guerra, entre os anosde1870 a 1889, por exemplo, sessenta estão em nome desses militares (são ou inválidos), sendo que quarenta e seis desses homens tiveram suas súplicas negadas por diversos motivos e catorze foram beneficiados fora dos prazos legais ${ }^{4}$.Entre estes, estava "o praça mutilado de guerra Pedro Rogério que, em 1866, havia perdido a perna esquerda em combate no Paraguay, ocasião em que recebeu baixa do exército" e “[...] tendo seu pedido deferido desde 1876, nada havia recebido do governo até o momento [em 1880]"5.

Interessante notar que, em outros documentos semelhantes aos acima citados - como os Ofícios despachados pela Presidência do Ceará a diversos Ministros[1876], nos quais se encontram também inúmeros requerimentos de pensão em nomes de praças veteranos do Paraguai - a situação quase não muda, posto que alguns dos pedidos analisados tinham sido aceitos pelo governo, mas quase nunca pagos nos prazos estipulados por lei e/ou decretos militares. Somente no dia 30 de novembro de 1876, sete súplicas de pensão em nomes de soldados Voluntários da Pátria foram enviadas pelo presidente do Ceará ao ministro da guerra, das quais se destacam duas: 
Tenho a honra de passar às mãos de V.Exa . a inclusa petição do soldado reformado do exército, Joaquim Jacintho de Miranda, em que solicita do governo imperial sua carta de pensão, que lhe foi concedida como voluntário da pátria, afim de que possa receber aqui esse vencimento

[...]

Tenho a honra de passar às mãos de V.Exa ${ }^{a}$ a inclusa petição do soldado reformado do exército, Antonio Francisco Carneiro, em que solicita do governo imperial sua carta de pensão, que lhe foi concedida como voluntário da pátria $[\ldots]^{6}$

Como se vê,os praças estavam na condição de reformados, mas o que significava ser um militar reformado? A partir da explicação, pode-se entender por que o destaque não foi aleatório.

No século XIX, existiam,nas instituições militares (como Exército e Marinha),diferenças entre Reforma e Aposentadoria.

As reformas (espécie de pensão) eram concedidas, geralmente, por invalidez irreversível -inaptidão por doenças crônicas e/ou amputações que impediam os homens de continuar no serviço das armas e também em outros serviços dentro dos quartéis. Sendo assim, um militar reformado era um indivíduo que portava algum tipo de invalidez. Já as aposentadorias eram outorgadas aos militares que "venciam" seu tempo de serviço ou nos casos em que os militares se encontravam em idade avançada, não tendo mais condições físicas de continuar nas forças armadas. Não necessariamente um militar aposentado era inválido ou inapto ${ }^{7}$.

As reformas militares, por se tratarem de auxílios financeiros, consistiam também em processos demorados e, certamente, aqueles ofícios não eram os primeiros que os praças reformados (inválidos) Joaquim de Miranda e João Carneiro tinham enviado.

Depois da guerra do Paraguai, as publicações de pedidos de pensão feitos por veteranos reformados passaram a ser mais comuns na imprensa. Na edição do dia 14 de julho de 1870 , o periódico Pedro II publicou dezenas de requerimentos de pensão, dos quais foram destacados apenas aqueles enviados por praças reformados:

\section{REQUERIMENTOS}

[...]

Antonio Ferreira Duarte, soldado reformado do $26^{\circ}$ corpo de voluntários da pátria, requerendo para the solicitar a sua carta de pensão.

Raymundo Alves Martins, soldado reformado do $36^{a}$ batalhão de infantaria. Idem Luiz de França Bispo, anspeçada reformado do $2^{\circ}$ batalhão de infantaria. Idem Manoel Pereira de Carvalho, soldado reformado do $14^{a}$ batalhão de infantaria.Idem Francisco Rodrigues da Cunha, soldado reformado do $9^{a}$ batalhão de infantaria.Idem Jose Ferreira, anspeçada reformado do $2^{\circ}$ batalhão de infantaria. Idem[... $]^{8}$ 
Entre os militares arrolados estava o soldado "Luiz de França Bispo, invalidado em 1866, no Paraguai que, desde o ocorrido, buscava na lei o amparo [...]". Em fevereiro de 1870, esse militar havia se identificado "como inválido por ferimentos que o levaram às doenças", mas “[...] como não informou quais moléstias lhe afetaram e não comprovou em qual hospital de campanha foi atendido ou internado, teve o pedido indeferido". Neste ínterim, as autoridades ministeriais disseram que "[...] ficaram informadas pela imprensa da capital da província que o inválido Luiz Bispo estava metido em desordens e que queriam informações[...]", dando a entender que esse seria mais um motivo para o pedido ser negado ${ }^{9}$.

De fato, alguns jornais de Fortaleza denunciaram a "má conduta" do praça Luiz Bispo. O jornal Pedro II, por exemplo, afirmou que:

\begin{abstract}
Pela repartição da policia se veio o conhecimento de que pelas 5 horas da tarde do dia 7 do corrente mez, nesta capital [Fortaleza], no outeiro da educandas, houve entre alguns guardas nacionais, inválidos e mulheres por ocazião de uma bebedeira na casa de Maria Prata, resultando disso serem feridos os guardas nacionais Paulino Pereira da Silva e Manoel Ferreira Silva.

O respectivo delegado, acudido logo, fez conduzir os offendidos para o quartel, a fim de serem socorridos, e prendeu o inválido Luiz França Bispo, Anna Rosa da Conceição, amasia deste, e Anna Maria do Espírito Santo, indigitados pelo clamor público como autores dos ferimentos [... ${ }^{10}$
\end{abstract}

Observando a cena, pergunta-se: qual a ligação entre o comportamento moral de um veterano e o indeferimento de seu pedido de pensão de guerra, quando se pensa que nas leis militares do exército vigentes até 1870, por exemplo, não existiam restrições diretas a esse respeito?Geralmente, o que havia era uma preocupação das autoridades das forças armadas em relação às condutas dos militares mobilizados, ou seja, aqueles que estavam na ativa. Porém, esse não era o caso. Mesmo não existindo base legal, os problemas pessoais dos excombatentes tinham relevância no andamento de seus processos, sobretudo, os que envolviam auxílios financeiros ${ }^{11}$.

Alguns inválidos, ao sentirem que a concessão da pensão era algo muito demorado e/ou distante,enveredavam por outros caminhos legais, a saber: pediam para ir ao Asilo dos Inválidos da Pátria.

De acordo com Marcelo Gomes, o Asilo dos Inválidos da Pátria estava localizado em Niterói, no Rio de Janeiro, e fora inaugurado, em agosto de 1868, pela "ação filantrópica" do governo imperial, tendo como funções primordiais: receber militares brasileiros regressos da "guerra contra Paraguai" que tinham adquirido incapacidade(s) física(s) no conflito e acolher 
os parentes desses homens. Porém, nem todos os inválidos eram bem vindos nessa instituição $\operatorname{asilar}^{12}$.

Em janeiro de 1873, o veterano do Paraguai João Nepomuceno de Oliveira pediu para ser asilado:

\begin{abstract}
Tenho a honra de transmittir a V.Ex. ${ }^{a}$ incluso o requerimento em que João Nepomuceno de Oliveira, ex-soldado do $8^{\circ}$ batalhão de Infantaria, pede para ser socorrido. Como informação, devo scientificar a V. Ex. ${ }^{a}$ que o estado de miséria a quê se acha reduzido o supplicante em consequiência de moléstia e ferimentos adquiridos na Campanha do Paraguay, dá-lhe direito a um lugar no Azilo de Inválidos dessa Côrte, no entanto S.M.Imperador designará de resolver em sua alta sabedoria como for servido.

Deos Guarde a V.Ex. ${ }^{a}$. Francisco de Assis Oliveira Maciel ${ }^{13}$
\end{abstract}

Ainda em 1873, João Nepomuceno foi asilado, mas, de acordo com as autoridades militares cariocas, haviaalgo de errado em sua estada no Asilo dos Inválidos. Um ofício enviado pelo ministério da guerra à presidência cearense pedia explicações sobre a modalidade de ingresso do referido soldado nas fileiras da guerra:

\begin{abstract}
Remetto a V.Ex. a o incluso requerimento em que o soldado do Azilo de Inválidos da Pátria, João Nepomuceno de Oliveira,allegando ser guarda nacional designado dessa província [do Ceará], pede que essa Presidência mande passar sua certidão de assentamento, visto ser considerado recrutado, afim de que V.Ex. ${ }^{a}$ preste esclarecimentos sobre o que pede o supplicante, mandando juntar a certidão requerida para ter o competente destino. Deos guarde a V.Ex. ${ }^{\text {a }} .^{14}$
\end{abstract}

A confusão das informações militares (sobre em qual força serviu e como aderiu à guerra) colocou João Nepomuceno na condição de suspeito. Desconfiadas, as autoridades ministeriais puseram em questão o seu alistamento. Como o asilo estava superlotado de inválidos, quaisquer desencontros de dados ou informações poderiam ser motivos para o deslocamento de contingente ${ }^{15}$. Sendo assim, o praça cearense teve de reiterar, em outro requerimento, sua qualidade de “designado da Guarda Nacional”, isto é, chamado pelo Estado para servir a pátria ${ }^{16}$.

Certamente, o "guarda nacional designado" João Nepomuceno buscou legitimidade no Decreto 3.383, de 21 de janeiro de 1865, no qual se outorgava que "as vantagens adscritas aos Voluntários da Pátria [...] abarcavam também os praças da Guarda Nacional que se apresentaram voluntariamente, isto é, as que não tivessem sido destacadas pelos decretos referentes à Guarda Nacional [...]”17. Por outro lado, a própria adesão de João à guerra, por meio do chamamento do Estado, dava-lhe respaldo para viver no Asilo. O certo é que a "categoria" recruta, assuntada pelas autoridades cariocas, mas negada pelo referido veterano, 
foi o principal motivo do ofício, uma vez que aos recrutados, os forçados, quase nada lhes era garantido.

Em fevereiro de 1874, o presidente do Ceará, Francisco Teixeira de Sá, explicava que “[...] mandou dar transporte para esta Côrte, de conta do Ministério da Guerra, aos inválidos da pátria alferes honorário do exército Joaquim Gomes Coutinho e o ex-cabo Antonio Raymundo Gomes, em vista do estado de penúria em que, de presente, aqui se achão" e que "rogava, por fim, a V.Ex. ${ }^{a}$ que attendendo as rasões acima expostas se dignasse de aprovar seu ato" ${ }^{18}$.Dias depois, o ministro da guerra reprovou a atitude daquela autoridade, avisando-a de "que tal despesa deveria ser a cargo da dita presidência"19.

Nem todos os militares inválidos queriam ser asilados. No final da guerra, muitos desejavam retornar às suas províncias, mas tiveram seus intentos dificultados por problemas financeiros. Em 1869, o jornal Cearense transcreveu do periódico A Opinião Liberal da Corte uma denúncia, na qual se ratificava a "injustiça e a desumanidade do ministro da guerra" em relação aos "bravos voluntários da pátria". O protagonista da história era um anônimo capitão do $26^{\circ}$ batalhão do Ceará que, na condição de inválido, ansiava o restabelecimento em casa:

\footnotetext{
- A Opinião Liberal da Côrte informa-nos ter se dado com um de nossos patrícios: um dos bravos do $26^{\circ}$ Batalhão de voluntários [da pátria] que agora se acha entre nós.

O Sr. Muritiba, de incansável prática de injustiça e deshumanidade. S. Ex. ${ }^{a}$ tem demonstrado plenamente o ódio entranhável à farda. Eis o facto:

"Um pobre capitão de voluntários da pátria, vindo por moléstias adquiridas em campanha, requerendo ao Sr. Ministro da guerra passagem para sua província, afim de gozar da licença que lhe foi concedida pela junta militar de saúde, e obteve do $\mathrm{S}$. Ex. ${ }^{\text {mo }}$ o seguinte despacho: - Dê a passagem descontada-se pela quinta parte [dosoldo].

Os voluntários da pátria que apreciem este procedimento do Sr. Muritiba. ${ }^{20}$
}

Após o conflito do Paraguai, ao que tudo indica, as autoridades imperiais pareciam mesmo não escutar, de imediato, os apelos dos veteranos. A imprensa de oposição à política imperial não perdoava essa postura. Inúmeras charges jocosas foram publicadas pelos jornais oposicionistas do Rio de Janeiro: 


\section{Charge 2- A Implacável surdez das autoridades do Império}

\section{Transcrição}

Os voluntários da pátria (que ainda não poderam obter respostas às suas justas reclamações) lançam mão d'esta nova receita para combater a implacável surdez de S. Ex ${ }^{\mathrm{a}}$... da guerra.

Fonte: BN/RJ. A Vida Fluminense. Rio de Janeiro. 27 de agosto de 1870.

*O título deste texto foi retirado desta charge.

**O alvo da charge é o ministro da guerra, o barão de Muritiba.

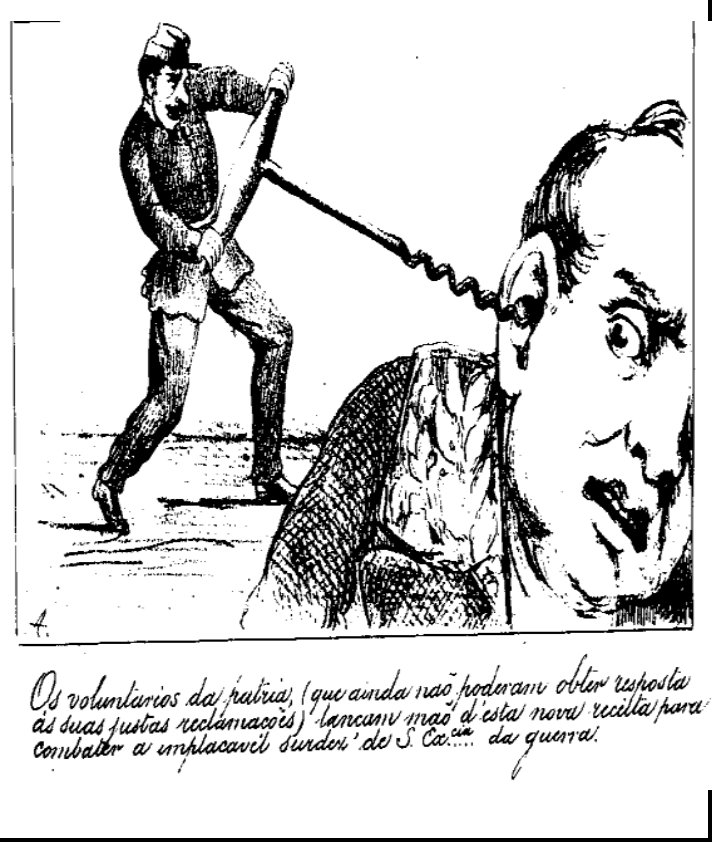

Diante da "implacável surdez das autoridades do Império", muitos praças veteranos preferiram pedir outros benefícios prescritos no decreto dos Voluntários da Pátria,como vantagens financeiras que não eram amparos permanentes, a exemplo dos "300 réis diários (prometidos no engajamento) e a gratificação de 300\$00", e“os prazos de terras de 22.500 braças nas colônias militares ou agrícolas, no momento de suas baixas",direitos estabelecidos no Art. $2^{\circ}$ do referido decreto.

De acordo com a edição de 12 de outubro de 1870 do Jornal Pedro II,o alferes Luiz Rodrigues Monteiro, “julgando-se com direito de receber o pagamento da gratificação 300\$00 dos voluntários, por ter se alistado por vontade própria na guerra,não obteve êxito em seu requerimento".Certamente, seu malogro devia-se, principalmente, a uma circular expedida pelo Ministério da Guerra à Presidência do Ceará, em 1867, que suspendia o benefício aos militares regressos.

Tenho a honra de acuzar o recebimento do aviso circular de V. Ex. ${ }^{\text {a }}$, de 9 do corrente mez, e fico inteirado de gratificação de $300 \$$ réis diários concedida aos voluntários 
da pátria sendo propriamente de campanha não deve continuar à ser abonada aos mesmos, desde que regressão ao império. Deos guarde a V. Ex..$^{21}$

Nesse caso, a burocracia militar agiu dentro da legalidade, mas não era dessa forma que os veteranos raciocinavam. A lógica desses militares era a de que a participação em um conflito, longo e demasiado violento, dava-lhes o direito ao ressarcimento. Sendo assim, se a ação era legal, porém não era justa em relação aos homens que arriscaram suas vidas nos campos de batalha paraguaios.

$\mathrm{O}$ sentimento de injustiça também penetrou nas mentes de outros veteranos da guerra. $\mathrm{O}$ militar alistado na "categoria recruta", segundo a legislação do exército, por exemplo, devido à sua adesão forçada na "instituição", nada tinha a receber dos cofres públicos; mesmo assim, muitos recrutados requereram alguns benefícios financeiros prometidos aos Voluntários da Pátria.

Antonio Pereira da Silva, "que dizia ter se alistado voluntariamente no conflito do Paraguai, requerendo o prêmio de voluntário, não teve seu pedido enviado às autoridades competentes por ordem do Barão de Ibiapaba, então presidente interino da província do Ceará". Segundo esta autoridade, aquele "indivíduo foi à guerra como recruta, por isso não se acha no direito de receber benesse alguma"22.

Utilizando-se da mesma estratégia, o soldado de infantaria João Marcolino Barbosa requereu os direitos de voluntário da pátria, mas seu pedido não convenceu as autoridades militares, porque estas desconfiaram que ele era um forçado. Por essa razão, o ministério da guerra exigiu da presidência cearense explicações sobre a forma de ingresso do excombatente:

\footnotetext{
Para que se possa verificar a qualidade de praça do soldado do $9^{\circ}$ batalhão de infantaria João Marcolino Barbosa, que se considera com direito aos favores concedidos aos Voluntários da Pátria, remmettendo a V.Ex. ${ }^{\text {a }}$, por copia, a nota das declarações por elle feita, afim de que V.Ex. ${ }^{a}$ informe si taesallegaçoes são verdadeiras, e si elle apresentou-se ou não voluntariamente para o serviço da guerra.Deos Guarde a V.Ex. ${ }^{\text {a23 }}$
}

Nesse caso, a desconfiança não foi confirmada nem negada; mas é possível que, durante a guerra, diante do alto índice de baixas no batalhão de Voluntários da Pátria do Ceará, o soldado Marcolino tenha sido ingresso nesse batalhão, tornando-se um voluntário da pátria de ocasião- uma prática militar bem recorrente durante a guerra do Paraguai. O certo é que o pedido do praça foi indeferido.

A desconfiança sobre os praças veteranos era tão forte que requerimentos simples, isto é, pedidos que, aparentemente, não estavam ligados a fatores financeiros, como solicitações 
de condecorações, diplomas e medalhas, eram-lhes dificultados e até mesmo negados. Este foi o caso do “"...] cabo d'esquadra do $16^{\circ}$ batalhão d'infantaria Joaquim Rodrigues do Nascimento que [em agosto de 1876],allegando ter feito a campanha do Paraguay desde seo começo até o fim, pede a V.Exa que lhe mande dar a respeitosa medalha e diploma [...]”. Ocorre que o referido militar já havia feito a mesma súplica meses antes e, certamente, por não ter recebido resposta, reenviou o pedido ${ }^{24}$.

Exemplos como esses também são recorrentes na imprensa de Fortaleza e nos documentos civis e militares da província do Ceará. Quais significados tinham,para os praças veteranos,insígnias como medalhas e diplomas? A resposta mais plausível é a de que tais distintivos serviriam como provas efetivas de suas participações na guerra, uma vez que muitos requerimentos de pensão enviados por aqueles militares eram indeferidos pelas autoridades imperiais sob a justificativa de que "os praças não tinham comprovações reais de suas presenças duradouras nos campos de batalha paraguaios" 25 .

Aquisição de terras foi outro direito muito desrespeitado nos requerimentos dos praças veteranos da guerra do Paraguai. "Praças como Joaquim Guerra Passos, Luiz Antonio Cabral e o músico da $3^{\circ}$ classe Conrado Pereira da Silva" exigiram "as terras prometidas pelo governo por terem pertencido ao corpo de voluntários da província do Ceará", porém todos obtiveram a mesma resposta "vazia" do presidente da província: "informe ao inspector da Thesouraria"26.

"Baixos oficiais" ou "oficiais subalternos", como alferes e capitães veteranos, também vivenciaram dramas semelhantes aos dos praças, quando procuraram seus direitos de guerra, junto às autoridades imperiais. Apesar de muitos desses militares terem sido ouvidos em suas súplicas, os auxílios financeiros eram quase sempre parcos, havendo uma inclinação das autoridades em anulá-los após a morte do veterano, fato que colocava as famílias dos excombatentes em difícil situação de sobrevivência ${ }^{27}$

A análise de algumas pensões concedidas a alferes mostrou valores irrisórios:

1)O alferes voluntário adido ao $14^{\circ}$ batalhão de infantaria [do Ceará], Procópio José Moreira, percebia a consignação mensal de $36 \$ 00$ para alimentar sua filha Casemira Alves Moreira.[...]/ Abril de 1868 [...]

2)João Soares Baptista Machado, alferes do $3^{\circ}$ Batalhão Infantaria do Exército, percebia, sem prejuízo do meio soldo, $18 \$ 00$ reis mensais de pensão pelos serviços que prestou na guerra do Paraguay[...]/outubro de 1870 [...]

3)[...] O alferes Luiz Rodrigues Monteiro recebia 21\$00 reis de pensão por ter sido voluntário da Patria.[...] outubro de $1870[\ldots]^{28}$ 
Em primeiro lugar, chama atenção a variação das quantias pagas aos alferes, sendo que as variantes dependiam do modo de engajamento do militar (voluntário ou não) e do batalhão ao qual estava vinculado (infantaria ou artilharia do exército ou infantes voluntários da pátria). Em seguida, observa-se que os valores estavam inclinados a diminuir no pós-guerra, sobretudo para os oficiais subalternos não voluntários da pátria.

Outra observação feita nas fontes manuscritas (civis e militares)do Cearáé que muitos desses oficiais haviam sido ressarcidos apenas com parte da pensão prometida. Era o que também ocorria com os oficiais subalternos invalidados na guerra que, segundo o ministro Muritiba, "não tinham participado de todo o conflito" e, por isso, "não tinham direito ao benefício por inteiro". Entretanto, a decisão do ministro não tinha base legal. Tratava-se de uma imposição cuja motivação, de acordo com a imprensa ilustrada carioca, remetia apenas às "questões pessoais, como o ódio e a antipatia" dessa autoridade em relações aos veteranos do Paraguai $^{29}$.

\section{Charge 3. Ministério da guerra e o modo como foram recebidos os voluntários da pátria}

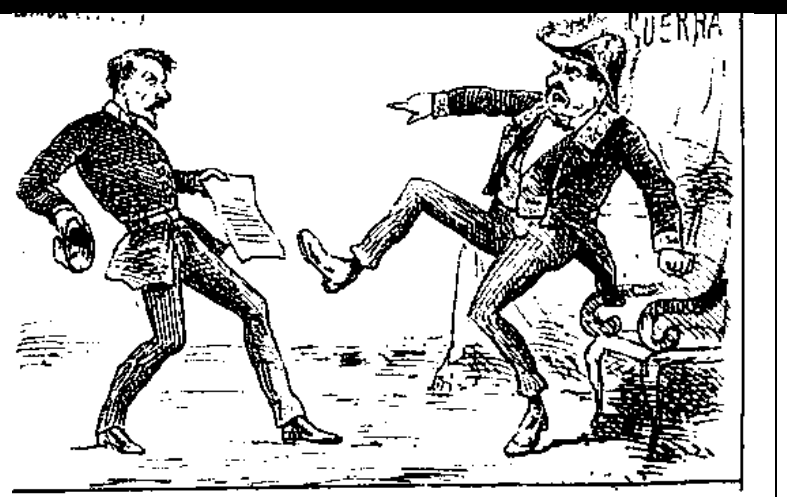

\section{Transcrição}

Maneira porque são recebidos alguns officiaes de voluntários que tem relações com os proprietários da Reforma*! Que governo!

BN/ RJ. Jornal A Vida Fluminense. Op.cit. 2 de abril de 1870.

*A palavra Reforma citada no texto refere-se ao jornal A Reforma- folha carioca que se autointitulava democrática; porém, na verdade,esse periódico coadunava-se com os Liberais do Rio de Janeiro, então contrários à política "conservadora" de d. Pedro II e de seus ministros.

Motivações pessoais ou não, o fato é que a decisão do ministro da guerra atrapalhou os intentos de praças e oficiais subalternos cearenses, voluntários e não voluntários. O caso de "Belarmino Accioly de Vasconcellos - alferes reformado do exército que allegava ter tido reforma por moléstia adquirida na guerra do Paraguay e que pedia a S. M. Imperial de 
conceder-lhe o soldo por inteiro de sua patente [...]" - datava de agosto de 1876; contudo,"havia para mais seis annos que ele insistia nesse pedido"30.

\section{A Crise Econômica do Brasil após a Guerra do Paraguai}

A década de 1870 fora apresentada na imprensa nacional como uma época de crise financeira ou econômica, devido aos gastos com a "guerra do Paraguai". Basta olhar, rapidamente, as notícias daqueles anos, para conferir a preocupação das autoridades imperiais em esclarecer o momento complicado do Brasil. De fato, isso não deixava "de ser uma verdade, mas não era toda a verdade", pois "o império ainda mantinha-se belicoso"- diziam os jornais liberais, Cearense e o A Reforma, folhas que faziam oposição ao governo imperial.

Segundo o historiador Francisco Doratioto, os custos com a Guerra do Paraguai causaram déficits que persistiram até 1889, pois os gastos empreendidos pelo governo brasileiro, durante esse conflito, chegaram a atingir 614 mil contos de réis, um número onze vezes maior que o valor orçamental em $1864^{31}$. Rui Granziera também confirma a crise por que passou a "nação brasileira", ressaltando "o extraordinário aumento da dívida pública interna representada pelas apólices emitidas para o financiamento da guerra»,32

O momento deficitário pelo qual passou o Brasil durante e, sobretudo, após o conflito com o Paraguai, não pode ser negado. Contudo, o colapso nas finanças não pode justificar os descasos do governo em relação aos militares regressos. A incapacidade políticoadministrativa do Império, por vezes flagrada na desorganização ou na confusão das informações contidas nos requerimentos de pensão, por exemplo, independia de fatores financeiros. A questão era de empenho e organização - condutas ausentes entre as autoridades imperiais.

Ademais, em meados de 1869, quando a guerra estava quase terminada, o Brasil instalou um governo provisório em Assunção, a capital paraguaia; o que significava arcar com os custos financeiros da manutenção das forças armadas nesta cidade, além das despesas dos recrutamentos direcionados ao Paraguai. Como explicar essas manobras, quando se dizia que a "nação brasileira" estava em crise econômica?

\section{Considerações Finais}

Oficialmente, a guerra do Paraguai terminou com a morte do presidente paraguaio, Solano Lopez,em $1^{\circ}$ de março de 1870 . Contudo,segundo Franscisco Doratioto, a instalação 
de um governo provisório paraguaio sob jugo político brasileiro, em agosto de 1869, permitiu que o clima hostil na região do Rio da Prata continuasse por, pelo menos, mais seis anos ${ }^{33}$.

Para manter o governo provisório no Paraguai, o Brasil continuou agindo de maneira beligerante, porque funções administrativas - a exemplo da manutenção do porto de Assunção e da segurança pública desta cidade - ficaram a cargo do exército brasileiro; o que explicava as constantes remessas de militares, incluindo infantarias cearenses, aquele país, após 1870.

O envio de tropas custava caro aos cofres públicos. Como o Império pôde mantê-lo? Talvez aí se tenha a resposta para a "implacável surdez das autoridades do Império" em relação aos benefícios dos veteranos da Guerra do Paraguai.

\section{Notas}

${ }^{1}$ Coleção das Leis do Império do Brasil de 1865. Rio de Janeiro: Typographia Nacional, 1865:3. [Tomo XXVIII, Parte II- Leis de 1865]. Conferir também o site: http://www.lexml.gov.br/urn/urn:lex:br:federal:decreto:1865-0107:337. (Último acesso: dezembro de 2015)

${ }^{2}$ SOUZA, Maria Regina Santos de. A Chama Pagada, A Chaga Aberta: a "Guerra do Paraguai", a Sociedade e os Militares Regressos. Ceará (1865-1889).2012, 227p. Tese de Doutorado em História/ Universidade Federal de Pernambuco (UFPE). Recife, 2012.

${ }^{3}$ Jornal Cearense. 02 de agosto de 1875. p.2 -Transcrição do Opinião Liberal [Aos Voluntários da pátria e às famílias dos que morreram na guerra]. Biblioteca Pública Meneses Pimentel/Fortaleza/CE (BPMP).

${ }^{4}$ Ao examinar as documentações dos Ministérios da Guerra e da Justiça, podemos enumerar algumasalegações que, repetidamente, são descritas como importantes motivos para os indeferimentos dos pedidos dos praças veteranos do Paraguai, a saber: documentação incompleta ou falta de documentação adequada, que comprove a participação efetiva e duradoura do combatente no conflito e "documentos falsos" que, segundos as autoridades daqueles ministérios, foram "produzidos para burlar as leis". Conferir também: SOUZA, 2012.p.135.

${ }^{5}$ Fundo: Presidência do Ceará ao Ministério da Guerra. Livro no ${ }^{\circ}$ 150. Requerimento enviado em 28 de agosto de 1880.Arquivo Público do Ceará (APEC).

${ }^{6}$ Fundo: Registro de Ofícios da Presidência do Ceará a diversos Ministros. Livro nº190 [1876]. 30 de novembro de 1876. APEC

${ }^{7}$ Coleção das Decisões do Governo do Império do Brasil de 1822. Imprensa Nacional: Rio de Janeiro, 1887.Biblioteca Nacional do Rio de Janeiro(BN/RJ).

${ }^{8}$ Jornal Pedro II, Fortaleza, 14 de julho de 1870.p. 1[Parte Official- Requerimentos].BPMP

${ }^{9}$ Fundo: Ministério da Guerra à Presidência do Ceará. Livro $\mathrm{n}^{\circ}$ 70. Requerimento enviado em 2 de fevereiro de 1870.APEC

${ }^{10}$ Jornal Pedro II, 18 de agosto de 1870. p.1. BPMP

${ }^{11}$ SOUZA, Maria Regina Santos de. A Chama Pagada, A Chaga Aberta: a "Guerra do Paraguai", a Sociedade e os Militares Regressos. Ceará (1865-1889), Tese de Doutorado em História/ Universidade Federal de Pernambuco (UFPE). Recife, 2012. p. 155-167.

${ }^{12}$ GOMES, Marcelo Augusto. "A Espuma das Províncias": um estudo sobre os Inválidos da Pátria e o Asilo dos Inválidos da Pátria, na Corte (1864-1930). 2006, 644p. Tese de Doutorado em História/ Universidade de São Paulo ( USP). São Paulo, 2006.

${ }^{13}$ Fundo: Presidência do Ceará ao Ministério da Guerra. Livro no 150 (1863-1876). Requerimento enviado em 13 de janeiro de 1873.APEC

${ }^{14}$ Fundo: Ministério da Guerra. Ofícios enviados à Presidência do Ceará. Livro no ${ }^{\circ 2(1873) . ~} 24$ de novembro de 1873.APEC 
${ }^{15}$ GOMES, Marcelo Augusto. “A Espuma das Províncias”: um estudo sobre os Inválidos da Pátria e o Asilo dos Inválidos da Pátria, na Corte (1864-1930). 2006,644p. Tese de Doutorado em História/ Universidade de São Paulo ( USP). São Paulo, 2006. Consultar oscapítulos 1 e 5.

${ }^{16}$ Fundo: Presidência do Cearáao Ministério da Guerra. Livro no ${ }^{\circ} 150.2$ de janeiro de 1874.APEC

${ }^{17}$ COSTA,Wilma Peres. A Espada de Dâmocles: o Exército, a Guerra do Paraguai e a Crise do Império. São Paulo: HUCITEC/UNICAMP,1996.p.229.

${ }^{18}$ Fundo: Presidência do Cearáao Ministério da Guerra. Livro n ${ }^{\circ} 150.4$ de fevereiro de 1874.APEC

${ }^{19}$ Fundo: Ministério da Guerra. IG'1. 02 de março de 1874.BN/RJ

${ }^{20}$ Jornal O Cearense, Fortaleza, 06 de julho de 1869. p.2 [Transcripção].BPMP. o $26^{\circ}$ batalhão do Ceará fora o único batalhão de Voluntário da Pátria da província do Ceará enviado à guerra do Paraguai.

${ }^{21}$ Fundo: Presidência do Ceará ao da Guerra. Livro n ${ }^{\circ} 149$ (1862-1870). 28 de maio de 1867.APEC

${ }^{22}$ Fundo: Presidência do Ceará ao Ministério da Guerra. Livro n ${ }^{\circ} 150.7$ de outubro de 1874.APEC

${ }^{23}$ Fundo:Ministério da Guerra à Presidência do Ceará:Livro n ${ }^{\circ} 73$ (1874-1875). 4 de novembro de 1874. APEC

${ }^{24}$ Fundo: Registro de Ofícios da Presidência do Ceará a diversos Ministros. Livro nº190 [1876]. Requerimento de 8 de agosto de 1876. APEC

${ }^{2525}$ Fundo: Ministério da Guerra à Presidência do Ceará . Livro n ${ }^{\circ} 73.17$ de outubro de 1873.APEC

${ }^{26}$ Jornal Pedro II. Fortaleza, 9 de outubro de 1870.p.2 [Parte Official-Requerimentos].BPMP

${ }^{27}$ SOUZA, Maria Regina Santos de. A Chama Pagada, A Chaga Aberta: a "Guerra do Paraguai", a Sociedade e os Militares Regressos. Ceará (1865-1889). 2012. Consultar o capítulo 4.

${ }^{28}$ Citação 1) Fundo: Ministério da Guerra:Ofícios enviados pela Secretaria do Estado dos Negócios da Guerra à Presidência do Ceará (1863-1906). Livro n 20. Ofício enviado em 24 de abril de 1868. Arquivo do Exército do Rio de Janeiro (AHEx/RJ.)

Citação 2) Jornal A Constituição. Fortaleza, 10 de outubro de 1870. p.2 [noticiário]. BPMP.

Citação 3) Fundo: Presidência do Ceará ao Ministério da Guerra. Livro n ${ }^{\circ} 150$. Requerimento de 12 de outubro de 1870. APEC

OBSERVAÇÃO: Para se ter uma idéia do alto custo de vida durante a "guerra do Paraguai", vejamos o quanto custava o preço da farinha de mandioca no Ceará, alimento básico da população pobre cearense: em 1866, o volume $(1 \mathrm{~kg})$ desse produto custava cerca de 60 a 80 réis. Depois do conflito, em 1870, diante da"crise financeira" vivenciada pelo Império, não se têm razões para crer que os preços dos alimentos baixaram.

${ }^{29}$ Jornal A Vida Fluminense. Rio de Janeiro. 2 de abril de 1870 . BN

${ }^{30}$ Fundo: Presidência do Ceará a diversos Ministros. Livro nº190 [1876]. Requerimento de 29 de agosto de 1876.APEC

${ }^{31}$ DORATIOTO, Francisco Fernando Monte oliva. O Conflito com o Paraguai: a Grande Guerra do Brasil. São Paulo: Ática, 1996.p.11

${ }^{32}$ GRANZIERA, Rui Guilherme. Guerra do Paraguai e o Capitalismo no Brasil. São Paulo: Editora da Unicamp/ HUCITEC, 1979. p.102.

${ }^{33}$ DORATIOTO, Francisco Fernando Monte oliva. Maldita Guerra: uma nova historia da guerra do Paraguai. Cia das Letras, 2002. p. 464.

\section{Referências Bibliográficas}

BEATTIE, Peter M. Tributo de Sangue: Exército, Honra, Raça e Nação no Brasil (18641945). (tradução Fábio Joly). São Paulo: EDUSP, 2009.

CARVALHO, José Murilo. Cidadania no Brasil: grande caminho. Rio de Janeiro: Civilização Brasileira, 2001.

CASTRO, Celso. IZECKSONH, Vitor.KRAY, Hendrich (orgs.). Nova História Militar Brasileira. Rio de Janeiro: FGV, 2004 (coletânea de textos).

COELHO, Edmundo Campos. O Exército e a política na sociedade brasileira. Rio de Janeiro: Forense Universitária, 1976.

COSTA, Wilma Peres. A Espada de Dâmocles: o Exército, a Guerra do Paraguai e a Crise do Império. São Paulo: HUCITEC/UNICAMP,1996.

DORATIOTO, Francisco Fernando Monteoliva. Maldita Guerra: uma nova historia da guerra do Paraguai. Cia das Letras, 2002. 
Paulo: Ática, 1996.

O Conflito com o Paraguai: a Grande Guerra do Brasil. São

DOURADO, Maria Teresa Garritano. A História esquecida da Guerra do Paraguai: fome, doenças e penalidades. 2010, 222p. Tese de Doutorado em História/ Universidade de São Paulo ( USP). São Paulo, 2010.

GOFFMAN, Erving. Estigma: Notas sobre a Manipulação da Identidade Deteriorada. (Tradução Márcia Bandeira de Mello Leite Nunes). Rio de Janeiro: Guanabara Koogan S.A. 1988. (4 edição)

GOMES, Marcelo Augusto. "A Espuma das Províncias”:um estudo sobre os Inválidos da Pátria e o Asilo dos Inválidos da Pátria, na Corte (1864-1930). 2006, 644p. Tese de Doutorado em História/ Universidade de São Paulo ( USP). São Paulo, 2006.

GRAHAM. Richard. O Brasil de meados do século XIX à Guerra do Paraguai. IN: História da América Latina. BETHELL, Leslie (Org.) São Paulo: EDUSP, 2001. p.771/828.

GRANZIERA, Rui Guilherme. Guerra do Paraguai e o Capitalismo no Brasil. São Paulo: Editora da Unicamp/ HUCITEC, 1979.

JESUS, Ronaldo Pereira. Visões da Monarquia: escravos, operários e abolicionistas na Corte. Belo Horizonte: ARGVMENTVM, 2009.

LOBO, Lilia Ferreira. Os Infames da História: pobres, escravos e deficientes no Brasil. Rio de Janeiro: Lamparina, 2008.

MARSON, Izabel; NAXARA, Márcia (Orgs). Sobre a Humilhação: sentimentos, gestos, palavras. Uberlândia, EDUFU, 2005. (coletânea de textos)

MENDES, Fábio Farias. A Economia Moral do Recrutamento militar no Império Brasileiro.IN: Revista de Ciências Sociais. São Paulo/USP, 1998. N³8. V.4. p.81/96.

MOLLAT, Michel. Os Pobres na Idade Média. (tradução Heloísa Jahn). Rio de Janeiro: Campus, 1989.

PERARO, Maria Adenir. Bastardos do Império. São Paulo: Contexto, 2001.

SCHWARCZ, Lilia Moritz.As Barbas do Imperador: D.Pedro II, um monarca nos trópicos. São Paulo: Cia das Letras, 1998.

SCHULZ, John. O Exército na Política: origem da intervenção militar (1850-1894). São Paulo: EDUSP, 1994.

SODRÉ, Nelson Werneck. História Militar do Brasil. São Paulo: Expressão Popular, 2010. ( $2^{\circ}$ edição)

SONTAG, Susan. Diante da Dor dos Outros. (Tradução Rubens Figueiredo). São Paulo: Cia das Letras, 2003.

SOUZA, Eusébio de. História Militar do Ceará. Fortaleza: Editora do Instituto Histórico do Ceará, 1950.

SOUZA, Maria Regina Santos de. Impactos da Guerra do Paraguai na Província do Ceará (1865-1870).2007, 173p. Dissertação de Mestrado em História/ Universidade Federal do Ceará (UFC). Fortaleza, 2007.

. A Chama Pagada, A Chaga Aberta: a "Guerra do Paraguai", a Sociedade e os Militares Regressos. Ceará (1865-1889).2012, 227p. Tese de Doutorado em História/ Universidade Federal de Pernambuco (UFPE). Recife, 2012.

URICOECHEA, Fernando. O Minotauro Imperial: a burocratização do Estado Patrimonial brasileiro no século XIX: Rio de Janeiro: Difel, 1978. 